\title{
Проблемы и перспективы дистанционного обучения в современной школе
}

Горошко Ю.Н.

ГБОУ ДПО РК «Крымский республиканский институт постдипломного педагогического образования», Симферополь, Российская Федерация.

(iD ORCID: https://orcid.org/0000-0003-1954-9493, e-mail: julg13@mail.ru

Резюме: Цель статьи - дать рекомендации по организации дистанционного обучения в школе, обозначив основные проблемы и перспективы его использования в учебном процессе. Методы исследования. В ходе исследования проведен анализ дистанционной фрормы обучения: выявлены области ее применения, проведена оценка достоинств и недостатков данной формы обучения, рассмотрены основные средства взаимодействия в интернет-среде при организации дистанционного обучения, выявлены наиболее эффрективные методы обучения в дистанционном формате. По результатам исследования были сделаны выводы о специфике дистанционной формы обучения. Автор подчеркивает, что основными достоинствами дистанционного обучения признаны индивидуальный подход, возможность поддерживать постоянную обратную связь между педагогом и учеником, отсутствие жесткого контроля как стимул к свободной творческой активности учащихся. В качестве главного недостатка дистанционной формы обучения обозначено отсутствие непосредственного общения с педагогом и сверстниками. Также делается вывод о том, что необходимо использовать коллективные методы обучения в дистанционном формате, чтобы преодолеть дефицит эмоционального общения. Наиболее эффективными методами обучения в формате дистанта признаны те, которые ориентированы на самостоятельную работу и творческий поиск. Отмечено, что дальнейшие перспективы развития дистанционного обучения связаны с обеспечением ряда условий: проведения этапа подготовительной работы для адаптации учебного материала, освоения информационных технологий и повышения уровня компьютерной грамотности, выбора оптимальных для дистанционного фрормата методов обучения.

Ключевые слова: дистанционное образование, современные педагогические технологии, информационные технологии в образовании, организация дистанционного обучения, развивающее обучение, творческие методы работы с учениками, проектная деятельность.

Для цитирования: Горошко Ю.Н. Проблемы и перспективы дистанционного обучения в современной школе // Развитие образования. - 2020. - № 2 (8). - C. 21-25. DOI:10.31483/r-75624.

\section{Problems and Perspectives of Distance Learning in Modern Schools}

\author{
Yuliya N. Goroshko \\ SBEI of FPE of the Republic of Crimea "Crimean Republican \\ Institute of Postgraduate Pedagogical Education", \\ Simferopol, Russian Federation. \\ iD ORCID: https://orcid.org/0000-0003-1954-9493, e-mail: julg13@mail.ru
}

\begin{abstract}
The purpose of the article is to give recommendations on the organization of distance learning at school, identifying the main problems and prospects for its use in the educational process. Methods of research. During the study, the analysis of distance learning was carried out. The field of its application is defined, assessment of the advantages and disadvantages of this form of learning is presented, the basic means of interaction in the online environment in distance learning are revealed, the most effective teaching methods in distance learning are pointed out. Based on the results of the study, conclusions were made about the specifics of distance learning. The author emphasizes that the main advantages of distance learning as following: an individual approach, the ability to maintain constant feedback between the teacher and the pupil, the lack of strict control as an incentive to free creative activity of pupils. The main disadvantage of distance learning is the lack of direct communication between the teacher and peers. It is also concluded that it is necessary to use collective methods of distance learning in order to overcome the deficit of emotional communication. The most effective methods of distance learning are those that are focused on independent work and creative search. It is noted that further prospects of distance learning development associated with number of following conditions: holding stage of the preparatory work for the adaptation of educational material, acquisition of information technologies and increase of the level of computer skills and choosing the optimal teaching methods for distance learning process.
\end{abstract}

Keywords: distance education, modern pedagogical technologies, information technologies in education, organization of distance learning, developmental teaching, creative methods of work with pupils, project activity.

For citation: Goroshko Y.N. (2020). Problems and Perspectives of Distance Learning in Modern Schools. Razvitie obrazovaniya $=$ Development of education, 2(8), 21-25. (In Russ.) DOI:10.31483/r-75624.

\section{Хальхи шкулӑн инс̧ет вӗрентӱпе с̧ыхӑннӑ йывӑрлӑхӗ тата пуласлӑхӗ}

Горошко Ю.Н.

КР «Крым Республикин диплом хыс̧с̧ӑнхи педагогика вӗренӗвӗ» ХПВ ПБВУ,

Симферополь, Рас̧с̧ей Патшалӑхе̌.

ID ORCID: https://orcid.org/0000-0003-1954-9493, e-mail: julg13@mail.ru

Аннотаци: Статьян тӗллевӗ - йывӑрлӑхпа пуласлӑха кӑтартса, шкулта инсетрен епле вӗрентес пирки сӗнӱ парасси. Тӗпчев меслечӗсем. Тӗпчев ирттернӗ май инс̧ет вӗрентӗвӗн фрормине тишкернӗ: унпа ӑс̧та-ӑс̧та усӑ курнине 
тупса палӑртнӑ, с̧ак вӗрентӱ фрормин лайӑх тата начар енӗсене хакланӑ, Интернет талккӑшӗнче килӗшӱллӗ ӗс̧лемелли хатёрсене пӑхса тухнӑ, дистанци фрормин чи тухӑс̧лӑ меслечӗсене тупса кӑтартнӑ. Тӗпчев кӑтартӑвӗсем тӑрӑх инс̧ет вӗренте̌вӗн уйрӑмлӑхӗ пирки пётӗмлетӱ тунӑ. Автор палӑртнӑ тӑрӑх, инс̧ет вӗрентӗвӗн чи лайӑх енӗ кашни вӗренекенпе уйрӑммӑн ӗс̧леме, педагогпа вӗренекен хушшинче татӑлми с̧ыхӑну тытма май пурри, ытла с̧ирӗп тӗрӗслеменнипе ачан творчествӑллӑ ӗс̧лес хавхи ӱсни пулса тӑрать. Инс̧ет вӗрентӗвӗн тӗп с̧итменлёхӗ тесе вӗренекенсем пӗр-пӗринпе тата вӗрентекенпе чӑн пурнӑс̧ри пек кӗрет хутшӑнӑва кӗрейменни тесе пӑхнӑ. Кунсӑр пус̧не автор, туйӑмлӑ хутшӑну тума, ушкӑнпа ӗслеме май паракан меслетсемпе усӑ курма сӗнет. Инсет вӗрентӱ формачӗн чи тухӑс̧лӑ меслечӗсем тесе ачана хӑй тӗллӗн ӗс̧леме, пултарулӑх картине кӗрсе шырав ирттерме май параканнисене йышӑнать. Автор кӑтартнӑ тӑрӑх, инс̧ет вӗрентӗве̌н аталану пуласлӑхӗ чылай условирен килет: вӗрентӱ материалне адаптацилемешкӗн хатӗрленӱ тапхӑрне ирттермелле, информаци технологине алла илмелле тата компьютер пӗлӗвне ӱстермелле, инс̧ет вӗрентёве тиве̌с̧терекен ку е вӑл меслете суйласа илмелле.

Tӗп сӑмахсем: дистанци вӗренӗвӗ, хальхи педагогика технологийӗсем, вӗренӱре усӑ куракан ку е вӑл информаци технологийӗ, инс̧ет вӗрентӗве йӗркелесси, аталантаракан вӗрентӱ, ачасемпе пултаруллӑ ӗс̧лемелли меслетсем, проект ецсеӗ-хӗлӗ.

Цитатӑлама: Горошко Ю.Н. Хальхи шкулӑн инс̧ет вӗрентӳпе с̧ыхӑннӑ йывӑрлӑхӗ тата пуласлӑхӗ // Вӗренӳ аталанӑвӗ. - 2020. - № 2 (8). - C. 21-25. DOI:10.31483/r-75624.

\section{Введение}

До недавнего времени дистанционное обучение представляло собой одну из перспективных альтернативных возможностей организации образовательного процесса, и в педагогическом сообществе велись дискуссии по поводу целесообразности и эффективности данной формы. Однако в условиях карантина дистанционное обучение стало не потенциальной возможностью, а необходимостью, в том числе для тех, кто не был к этому готов. Особенно актуальными для педагогов стали вопросы: как организовать дистанционное обучение, какие средства взаимодействия в информационной среде использовать и какие методы обучения являются наиболее эффективными в дистанционном формате. Цель cmambu - дать ответы на эти вопросы, обозначив основные проблемы дистанционного обучения и перспективы его использования в учебном процессе.

\section{Методы исследования}

Для достижения поставленных в статье целей проведем анализ дистанционной формы обучения. Для этого сравним дистанционную форму обучения с другими формами, обозначим ее основные области применения, проведем оценку достоинств и недостатков данной формы обучения, проанализируем основные средства взаимодействия в интернет-среде при организации дистанционного обучения, выявим наиболее эффективные методы обучения в дистанционном формате и дадим рекомендации по их использованию.

Дистанционное обучение - это процесс передачи и формирования ЗУН с помощью удаленного взаимодействия между учеником и педагогом. Следует отметить, что дистанционное обучение строится в соответствии с теми же целями и дидактическими принципами, что и очное обучение. Отличие дистанционного обучения заключается в принципах организации, обусловленных спецификой информационной среды, в которой оно осуществляется. В отличие от заочной формы, дистанционное обучение предполагает постоянную обратную связь с педагогом, которая реализуется с помощью современных информационно-коммуникационных технологий.

Можно выделить следующие области применения дистанционного обучения: профессиональная подготовка и переподготовка кадров; повышение квалификации педагогических кадров; подготовка школьников по отдельным учебным предметам к сдаче экзаменов экстерном; подготовка школьников к поступлению в учебные заведения; углубленное изучение определенных тем, разделов из школьной программы или вне школьного курса; ликвидация пробелов в знаниях, умениях, навыках школьников по отдельным предметам школьной программы; базовый курс школьной программы для учащихся, не имеющих возможности посещать школу вообще или в течение какого-то отрезка времени; дополнительное образование [2; 4].

\section{Достоинства и недостатки}

\section{дистанционного обучения}

Дистанционное обучение, как и любая другая форма обучения, имеет свои достоинства и недостатки. К достоинствам можно отнести:

- индивидуальная организация процесса обучения, помогающая подстроиться к потребностям и особенностям ребенка. Возможность для ученика подобрать индивидуальный темп обучения, самостоятельно и гибко планировать время и продолжительность занятий;

- большая степень свободы ученика по сравнению с традиционной формой обучения;

- организация постоянной обратной связи между учеником и учителем, которая может выходить за рамки строго ограниченного времени урока;

- использование в образовательном процессе новейших достижений информационных и телекоммуникационных технологий, что может повышать интерес учеников к учебе;

- открываются возможности для повышения популярности и эффективности методов обучения, связанных с развитием креативности обучающихся, создаются условия для творческого самовыражения учеников;

- открывается доступ к обширным информационным ресурсам, недоступным во время обычных уроков в традиционном формате обучения;

- работа с дистанционными технологиями способствует формированию компетентности в использовании ИКТ, повышает компьютерную грамотность, что является очень важным в современном информационном обществе.

Недостатки дистанционного обучения:

- новая форма обучения предполагает длительный предварительный этап подготовки и проектирования адаптации учебного материала, разработки учебного курса, методов взаимодействия. В условиях карантина 
не было времени для проведения этого подготовительного этапа;

- недостатки технического оснащения. Для успешного осуществления дистанционного обучения необходимо наличие компьютерной техники, быстрого Интернета;

- низкий уровень компьютерной грамотности. Несмотря на популярность и повсеместное распространение информационных технологий, ощущается недостаток знаний в данной сфере для эффективной организации дистанционного обучения. Это касается учеников, их родителей и даже педагогов;

- один из главных недостатков дистанционного обучения, который ничем невозможно компенсировать, - отсутствие непосредственного, живого общения с педагогом. Урок теряет эмоциональную окраску, что ведет к снижению интереса учеников к материалу. Особую проблему представляет организация воспитательного процесса в условиях дистанта. Воспитательное воздействие очень сложно осуществить без непосредственного общения с педагогом, и тут не могут помочь никакие самые совершенные технические средства;

- в условиях дистанционного обучения сложно организовать практические занятия;

- необходимость жесткой самодисциплины, которой зачастую не хватает учащимся в условиях дистанта;

- снижение мотивации к учебе в связи с невозможностью организовать строгий контроль над выполнением заданий и адекватную систему поощрений за успехи. Недостатки в организации дистанционного обучения приводят к непониманию и дезориентированности учеников, что также снижает их мотивацию.

\section{Средства взаимодействия в интернет-среде} при организации дистанционного обучения

Одно из наиболее простых средств взаимодействия в информационной среде - электронная почта. Ею умеют пользоваться практически все педагоги, родители и учащиеся. С помощью электронной почты можно отправлять задания для учеников, текстовые материалы, презентации, ссылки на интернет-ресурсы по предмету и т. д. Достоинством электронной почты является возможность персонального общения с каждым учеником, выстраивания индивидуальной траектории обучения. Однако данный способ взаимодействия требует много времени из-за необходимости постоянно отслеживать сообщения от учеников и индивидуально отвечать каждому. Также существенным недостатком электронной почты является невозможность коллективного взаимодействия, публичных обсуждений.

В последнее время еще более популярной формой взаимодействия в информационной среде становятся такие мобильные приложения, как Viber, WhatsApp. Также как и электронная почта, они предоставляют возможность осуществлять индивидуальное общение с учениками, отправлять текстовые материалы, фото, видео, аудио, ссылки на интернет-ресурсы и т. д. Однако они имеют ряд преимуществ. Мобильные приложения позволяют более оперативно отправлять и получать сообщения, обмениваться информацией. Зачастую электронную почту открывают только на ПК и в тече- ние дня могут не отслеживать входящих сообщений, а мобильные телефоны всегда под рукой, и сообщения мобильных приложений не остаются незамеченными. Также важным преимуществом указанных мобильных приложений является возможность коллективного общения в группах и сообществах.

Широко распространенным и легким в использовании средством ДО является электронный журнал. Учитель направляет учащимся через электронный журнал задания, определяя форму и сроки их выполнения. Учащиеся встречно направляют учителю выполненные в электронном виде ответы или фотоотчеты работ. Дети занимаются по стандартной образовательной программе, используя учебники. Однако в электронном журнале можно также прикреплять дополнительные материалы: видеолекции, видеоуроки, презентации.

Проводить онлайн-занятия в дистанционном формате можно через специальные платформы Zoom, Moodle.

Организация видеоуроков на бесплатной основе возможна через сервис YouTube. На канале YouTube в режиме прямых трансляций организуется видеовстреча с учащимися. Проведенная видеотрансляция может быть сохранена для последующего использования в общем доступе.

Большие возможности для дистанционного обучения предоставляют сервисы Google. Документы Google можно использовать для создания текстов, электронных таблиц, презентаций, анкет, календарей, организации коллективной работы над проектом.

Для дистанционного обучения можно использовать блоги. Блог (англ. blog, от web log - интернет-журнал событий, интернет-дневник, онлайн-дневник) - вебсайт, основное содержимое которого - регулярно добавляемые человеком записи, содержащие текст, изображения или мультимедиа. На настоящий момент платформой для блога может быть что угодно - личный сайт, канал на YouTube, канал в Telegram, инстаграм-страничка, публичная страница Вконтакте и т. д.

Ведение блога позволяет учителю представлять в Интернете свои методические разработки, размещать ссылки на web-peсурсы; осуществлять обратную связь с учениками, публиковать домашние задания, проводить тестирование учащихся, организовывать коллективную работу online, размещать мультимедийные ресурсы к урокам. Для учеников данная форма взаимодействия позволяет расширить информационное пространство, повысить мотивацию изучения предмета, получать материалы для уроков в режиме online и дополнительную информацию для творческого развития, поддерживать обратную связь с учителем.

\section{Методы обучения в дистанционном формате}

Работа с текстом - один из наиболее распространенных методов, который хорошо подходит и для формата дистанционного обучения. В соответствии с требованиями ФГОС следует отказаться от репродуктивных форм работы, заменяя их самостоятельной познавательной деятельностью обучающихся. Это особенно актуально для работы учеников в формате дистанта, когда ресур- 
сы Интернета располагают к исследованию. Работа с текстами должна быть построена таким образом, чтобы мотивировать ученика к самостоятельному поиску. Текст не должен содержать прямых ответов на вопросы. Нужно выбирать или составлять такой текст, который предполагает работу с информацией: выделение главного, самостоятельное обобщение, оценка, получение в результате нового информационного продукта - выводов. Такие задания называют продуктивными, и они составляют основу развивающего обучения.

Обучение в дистанционном формате предполагает активизацию креативных способностей учеников, поэтому особую актуальность приобретают творческие методы работы. Эффективным творческим методом является написание эссе. Эссе - литературный жанр, прозаическое сочинение небольшого объёма и свободной композиции, подразумевающее впечатления и соображения автора по конкретному поводу или предмету. Учащимся можно предложить темы творческих работ на выбор. Важно, чтобы они были оригинальными, стимулировали фантазию, образное мышление и позволяли переосмыслить информацию с новых позиций, провести параллель между событиями прошлого и современностью. Возможная форма работы - написание эссе-размышления на определенную тему по выбору ребенка. Можно предложить тему, на которую нельзя дать однозначный ответ, чтобы дети предложили разные точки зрения.

В формате дистанта необходимо организовывать и коллективные формы работы. Для этого можно воспользоваться платформой, позволяющей осуществлять онлайн-общение. Одним из наиболее эффективных методов коллективной работы являются моральные дискуссии. Главная цель проведения учебных дискуссий - развитие критического мышления школьников, формирование их коммуникативной культуры. Учебная дискуссия основана на диалоге, строится не просто на поочередных высказываниях, вопросах и ответах, но на обращении учеников друг к другу, стимулирует инициативность учащихся. В условиях вынужденного карантина, когда ученики испытывают острый дефицит общения со сверстниками, такой метод приобретает особую актуальность, хотя требует использования особых платформ, на которых можно организовать коллективную дискуссию.

Эффективным методом в формате дистанционного обучения является создание галереи образов. Указанный метод как раз позволяет в полной мере воспользоваться ресурсами сети Интернет для подбора подходящих визуальных материалов. Содержанием галереи образов может стать любой наглядный материал: фотографии, иллюстрации, репродукции картин, фотографии музейных экспозиций. Галерею образов целесообразно оформить в виде презентации, где каждый кадр будет сопровождаться краткой аннотацией. Составление аннотаций в презентации поможет закрепить теоретические сведения по соответствующим темам и лучше осмыслить материал.

Дистанционный формат обучения можно эффективно использовать для проведения виртуальных экскур- сий. На настоящий момент многие интернет-ресурсы предоставляют возможность совершать виртуальные путешествия по ведущим музеям, картинным галереям, известным культурным объектам. В частности, на pecypce Google Art Project представлены экспонаты художественных музеев и картинных галерей мира, 3D-модели залов позволяют в реальном времени «путешествовать» по музеям, получать справочную информацию в виде текстов и аудиофайлов. Информация структурирована в соответствии с направлениями живописи, есть также подборки картин конкретных художников. Большинство картин представлено в высоком разрешении, что позволяет зрителю разглядеть мельчайшие детали художественного произведения, недоступные при использовании репродукций.

В последнее время наиболее актуальной из инновационных педагогических методик становится работа с проектами. Это обусловлено тем, что реализация проектов способствует развитию социальных компетентностей, которые пригодятся и в профессиональной, и в личной сфере. К их числу относятся умение решать проблемы, умение работать в команде, умение осуществлять деловую коммуникацию и участвовать в дискуссии, умение критически относиться к проблемам, умение работать с информацией [1].

Метод проектов всегда ориентирован на самостоятельную деятельность учащихся и всегда предполагает решение какой-то проблемы. А решение проблемы предусматривает, с одной стороны, использование разнообразных методов и средств обучения, а с другой - необходимость интегрирования знаний и умений из различных сфер науки, техники, технологии, творческих областей [3]. Проект всегда имеет реальный практический результат, что является безусловным достоинством данного метода. Целесообразность использования метода проектов при дистанционном обучении обусловлена тем, что работа над проектом во многом связана с самостоятельным поиском и обработкой информации, что особенно удобно делать с помощью интернет-ресурсов.

\section{Результаты}

На основе проведенного исследования можно сделать следующие выводы:

1. Дистанционная форма обучения отличается от других форм не целями, но принципами организации, обусловленными спецификой информационной среды.

2. К основным достоинствам дистанционного обучения можно отнести индивидуальный подход к организации обучения и выстраивания его траектории; возможность поддерживать постоянную обратную связь между учеником и учителем, не ограниченную временем урока; определенную степень свободы, которой так не хватает ученикам в формате обычного школьного обучения. Главный недостаток дистанционной формы обучения - отсутствие непосредственного, живого общения с педагогом и сверстниками.

3. Современные интернет-ресурсы предоставляют самые разнообразные средства взаимодействия в виртуальной среде, которые можно использовать при 
организации дистанционного обучения. Каждый педагог может выбрать для себя наиболее удобную и оптимальную. Для компенсации дефицита живого общения обязательно использование таких средств, которые позволяют организовать интерактив, коллективное обсуждение или видеосвязь.

4. Наиболее эффективными методами обучения в формате дистанта являются те, которые ориентированы на самостоятельную работу и творческий поиск, поскольку этому способствует виртуальная среда. В то же время нужно использовать и коллективные методы обучения, которые позволяют «оживить» дистанционный формат общения.

\section{Обсуждение}

Дистанционное обучение является перспективной формой обучения в современной школе. Вынужденный повсеместный переход на данную форму показал, что она вполне жизнеспособна и может использовать- ся не только для системы высшего и дополнительного профессионального образования, но и в основной и даже в начальной школе. В то же время были выявлены и проблемы дистанционного обучения в современной школе, которые требуют внимания для дальнейшего преодоления. Для эффективной организации данного формата необходимо обеспечить ряд условий: проведение подготовительной работы для адаптации учебного материала; освоение информационных технологий для успешного взаимодействия с учениками в виртуальной среде; повышение компьютерной грамотности учеников и педагогов; выбор методов обучения, позволяющих наилучшим образом реализовать образовательные цели и задачи в режиме дистанционного обучения. В условиях информационного общества дистанционное обучение все равно будет развиваться, в том числе в школьном образовании, и задача современных педагогов - способствовать этому развитию и успешному внедрению.

\section{Список литературы}

1. Иванов Д.А. Компетенции и компетентностная модель современного учителя [Электронный ресурс]. Режим доступа: https://nsportal.ru/shkola/materialy-metodicheskikh-obedinenii/library/2015/03/26/kompetentsii-ikompetentnostnaya-model

2. Кидакоева Л.У. Дистанционное обучение в школе [Электронный ресурс]. - Режим доступа: https://nsportal. ru/shkola/administrirovanie-shkoly/library/2019/11/06/distantsionnoe-obuchenie-v-shkole

3. Новые педагогические и информационные технологии в системе образования / Е.С. Полат, М.Ю. Бухаркина, М.В. Моисеева [и др.]. - М.: Академия, 2008. - 272 с.

4. Полат Е.С. Дистанционное обучение [Электронный ресурс]. - Режим доступа: https:/gigabaza.ru/ doc/101024.html

\section{References}

1. Ivanov, D. A. Kompetentsii i kompetentnostnaia model' sovremennogo uchitelia. Retrieved from https://nsportal. $\mathrm{ru} /$ shkola/materialy-metodicheskikh-obedinenii/library/2015/03/26/kompetentsii-i-kompetentnostnaya-model

2. Kidakoeva, L. U. Distantsionnoe obuchenie v shkole. Retrieved from https://nsportal.ru/shkola/administrirovanieshkoly/library/2019/11/06/distantsionnoe-obuchenie-v-shkole

3. Polat, E. S., Bukharkina, M. Iu., \& Moiseeva, M. V. (2008). Novye pedagogicheskie i informatsionnye tekhnologii v sisteme obrazovaniia., 272. M.: Akademiia.

4. Polat, E. S. Distantsionnoe obuchenie. Retrieved from https://gigabaza.ru/doc/101024.html

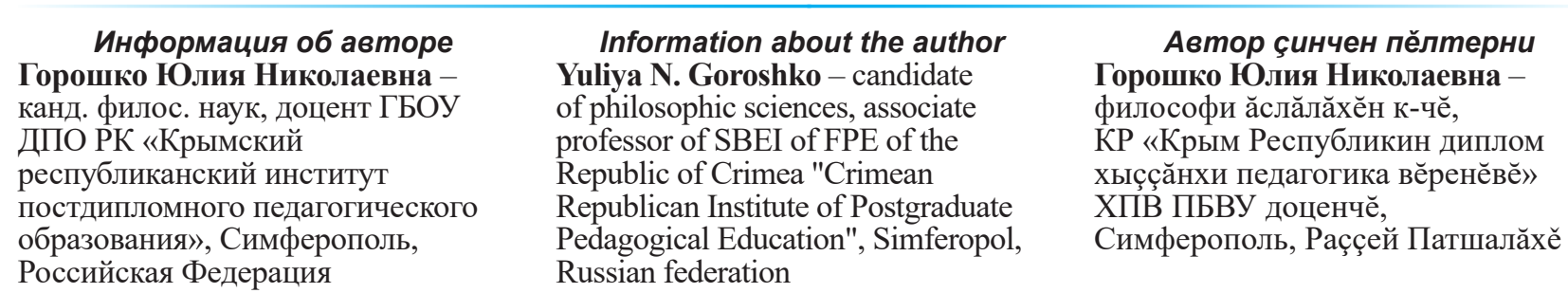

